SISTEMA
ELETRÔNICO
DE REVISTAS
SER I UFPR

\title{
Comunicação e a Convenção sobre Diversidade Biológica: uma leitura sobre o Parque Estadual da Ilha Grande (Rio de Janeiro, Brasil) e o Parque Natural da Maremma (Toscana, Itália)
}

\section{Communication and the Convention on Biological Diversity: a reading on the Ilha Grande State Park (Rio de Janeiro, Brazil) and the Maremma Natural Park (Tuscany, Italy)}

\author{
Elizabeth OLIVEIRA ${ }^{1 *}$, Marta de Azevedo IRVING ${ }^{1}$, Lionello Franco PUNZO² \\ ${ }^{1}$ Universidade Federal do Rio de Janeiro (UFRJ), Rio de Janeiro, RJ, Brasil. \\ ${ }^{2}$ Universidade de Siena, Itália. \\ *E-mail de contato: elizabetholiverbr@gmail.com
}

Artigo recebido em 14 de dezembro de 2017, versão final aceita em 30 de junho de 2018.

RESUMO: A conservação da biodiversidade representa uma demanda contemporânea de grande complexidade. Em cenários de crise ambiental, diversos grupos sociais têm buscado influenciar o processo de tomada de decisão, por meio de pactos como a Convenção sobre Diversidade Biológica (CDB), principal acordo internacional orientador de políticas públicas dirigidas a essa agenda. No âmbito da CDB, a comunicação é reconhecida como um componente fundamental para a sensibilização da sociedade sobre a importância dessa temática. Partindo desse pressuposto e considerando o papel estratégico das áreas protegidas para a conservação da biodiversidade global, o objetivo deste artigo é interpretar como as ações de comunicação se expressam na gestão de duas áreas protegidas localizadas em contextos geográficos, socioeconômicos e ambientais distintos. Neste recorte, foram selecionados o Parque Estadual da Ilha Grande, no Rio de Janeiro, Brasil, país líder mundial em diversidade biológica; e o Parque Natural da Maremma, região da Toscana, Itália, país que responde pela maior biodiversidade da União Europeia. Com base em pesquisa bibliográfica e documental, entrevistas com interlocutores da gestão pública e análise de ferramentas de comunicação virtuais disponíveis, foi possível avaliar que há ações em curso, em ambos os parques. Porém, considerando que, dentre as 20 Metas de Aichi (pactuadas pela CDB para 2011-2020), a Meta 1 remete à sensibilização da sociedade sobre a relevância da biodiversidade, diferenças evidentes são observadas em relação à maneira como a gestão de cada parque gera e divulga suas informações, o que tende a influenciar o alcance dessa meta, em cada caso. 
Palavras-chave: áreas protegidas; Convenção sobre Diversidade Biológica; comunicação; Parque Estadual da Ilha Grande; Parque Natural da Maremma.

ABSTRACT: Biodiversity conservation represents a complex contemporary demand. In scenarios of environmental crisis, social groups have been trying to influence the decision-making process through pacts such as the Convention on Biological Diversity (CBD). CBD is the main international agreement that guides public policies related to this agenda. Within the framework of the $\mathrm{CBD}$, communication is recognized as a fundamental component for raising awareness concerning this important issue. Based on this premise and considering the strategic role of protected areas for the conservation of global biodiversity, the purpose of this article is to understand how communication itself is expressed in the management of two protected areas located in different contexts. In this sense, we selected Ilha Grande State Park, in the state of Rio de Janeiro, Brazil (country with the biggest biological diversity in the world), and Maremma Natural Park, located in the Tuscany region, Italy (responsible for the greatest biodiversity of the European Union). Based on bibliographical and documentary research, interviews with interlocutors from the public management, and analysis of the available online tools for communications, we could evaluate that there are ongoing actions in both parks. However, considering that Target 1 from the 20 Aichi Targets (agreed by the CBD for 2011-2020) refers to the social awareness regarding the biodiversity relevance, visible differences are observed when it comes to the form that each park creates/releases this information. This situation may influence the appropriate achievement of this goal in each case.

Keywords: protected areas; Convention on Biological Diversity (CBD); communication; Ilha Grande State Park; Maremma Natural Park.

\section{Introdução}

A biodiversidade, ou diversidade biológica ${ }^{1}$, é formada por plantas, animais, microrganismos e as relações ecológicas que sustentam todas as formas de vida essenciais ao equilíbrio planetário e ao bem-estar humano. Esse patrimônio natural é fundamental para assegurar à sociedade o fornecimento de alimentos, fibras e medicamentos, assim como favorecer a proteção das fontes de água doce, a estabilidade climática, além de outros benefícios ambientais, socioeconômicos e simbólicos (MEA, 2005).
Considerando a importância central desta temática, a crescente perda de biodiversidade vem sendo caracterizada como um dos maiores dilemas contemporâneos e a necessidade de conservação desse patrimônio surge como um grande desafio. Desde a década de 1990, essa problemática vem sendo reconhecida como uma questão de responsabilidade e alcance globais, motivada pela atuação do movimento ambientalista, pelo avanço científico que permitiu o aprofundamento de estudos sobre os riscos associados a esse processo e, também, pelo aumento da cobertura jornalística sobre essa agenda (Hannigan, 2009).

\footnotetext{
${ }^{1}$ No âmbito da Convenção sobre Diversidade Biológica, a biodiversidade significa: "a variabilidade de organismos vivos de todas as origens, compreendendo, dentre outros, os ecossistemas terrestres, marinhos e outros ecossistemas aquáticos e outros ecossistemas aquáticos e os complexos ecológicos de que fazem parte; compreendendo ainda a diversidade dentro de espécies, entre espécies e de diferentes ecossistemas" (MMA, 2000, p. 9).
} 
Os riscos à sobrevivência de muitas espécies têm sido ilustrados pela divulgação periódica da chamada Lista Vermelha de animais e plantas ameaçados de extinção. Tal cenário tem ampla relação com as atividades humanas - degradação de habitats, agravamento das mudanças climáticas, poluição, sobre exploração dos recursos naturais e presença de espécies exóticas invasoras, segundo o relatório Global Biodiversity Outlook 3-GBO3 (SCBD, 2010).

A busca de soluções para os dilemas mencionados tem perpassado as preocupações e ações de vários segmentos sociais. Essas articulações têm refletido, nas duas últimas décadas, no âmbito do processo de implementação da Convenção sobre Diversidade Biológica - CDB (MMA, 2000). A CDB é considerada o principal pacto internacional construído com o objetivo de orientar essa agenda complexa e marcada por controvérsias (Bensusan, 2014; Prates \& Irving, 2015).

No âmbito da CDB, a disseminação de ações de comunicação tem importância central para ampliar a compreensão da sociedade sobre a complexidade dessa temática, embora a materialização dessa orientação também seja considerada como uma questão desafiadora em nível global (Hesselink et al., 2007). Para fazer frente a esse e a outros desafios foram estabelecidas as 20 Metas de Aichi ${ }^{2}$ (importantes deliberações globais, pactuadas no âmbito da CDB para implementação no período 2011-2020, cujo recorte, mencionado a seguir, inspira a discussão deste artigo).
Considerando que no âmbito da CDB os parques e outras áreas protegidas são reconhecidos pela importância central para a conservação da biodiversidade, assim como a complexidade que envolve a implementação dessa Convenção, sobretudo, em relação à disseminação de informação qualificada sobre a agenda em questão, o objetivo deste artigo é interpretar como as ações de comunicação se expressam na gestão de dois parques inseridos em países distintos: um na América Latina e outro na União Europeia. Tendo em vista os diferentes contextos geográficos, ecológicos, políticos e socioeconômicos aos quais os parques pesquisados estão associados, cabe ressaltar que a ideia não foi produzir um estudo comparativo, mas refletir sobre potenciais avanços, dilemas e lições aprendidas a partir dessas duas experiências de comunicação estudadas. Essa interpretação, por sua vez, teve como inspiração a Meta 1 de $A i c h i^{3}$, que remete à necessidade de sensibilização da sociedade sobre a importância da biodiversidade, questão que pressupõe acesso à informação qualificada. Para tal, se buscou, ainda, incorporar a esse debate uma perspectiva interdisciplinar. Nesse sentido, a temática da comunicação é abordada em interface com outras áreas do conhecimento. É o caso de áreas como a antropologia, biologia, ecologia social, sociologia e economia, representadas neste artigo por referências escolhidas para promover o diálogo proposto.

Como cenários para a realização desta pesquisa qualitativa e com base nos enfoques que fundamentaram este artigo, foram selecionados o

\footnotetext{
${ }^{2}$ Conteúdo completo disponível em: $<$ https://www.cbd.int/sp/targets/>. Acesso em: fev.2016

${ }^{3}$ Meta 1 de Aichi: “Até 2020, no mais tardar, as pessoas terão conhecimento dos valores da biodiversidade e das medidas que poderão tomar para conservá-la e utilizá-la de forma sustentável.” Fonte: $<$ http://www.mma.gov.br/perguntasfrequentes? catid=33>. Acesso em: jan.2016.
} 
Parque Estadual da Ilha Grande (PEIG), localizado no Rio de Janeiro, Brasil, país líder em diversidade biológica em nível mundial (Lewinsohn \& Prado, 2005); e o Parque Natural da Maremma, situado na região da Toscana, Itália, país que responde pela maior biodiversidade da União Europeia (MATTM, 2014). A seleção se justifica por ambos os parques se inserirem em regiões costeiras sujeitas ao crescimento do turismo de massa, entre outros tipos de pressões. Tais estruturas também foram criadas na mesma época - década de 1970 -, com o intuito de resguardar patrimônios naturais e culturais inestimáveis de diversas ameaças. O PEIG, além de ser terceiro mais antigo do Estado do Rio de Janeiro (Vallejo, 2005a), é o segundo maior parque insular do Brasil (INEA, 2013). Já o Parque da Maremma foi a primeira área protegida instituída na região da Toscana (Regione Toscana, 2009).

Com base nesses pressupostos, o percurso metodológico teve a realização de uma pesquisa na Itália entre março e junho de 2015 como ponto de partida ${ }^{4}$. Nesse período, foram realizadas as atividades de levantamento bibliográfico e documental em portais de instituições governamentais e não governamentais italianas; visita ao Parque Natural da Maremma; entrevistas com dois interlocutores ${ }^{5}$ que contextualizaram como as ações de comunicação se inseriam no processo de gestão dessa área protegida; além de uma análise das principais ferramentas virtuais de disseminação de informações para a sociedade. Para fins de elaboração deste artigo, ao longo de 2016 e até julho de 2017, essas mídias foram revisitadas para eventuais atualizações.
Partindo da mesma metodologia, as atividades relacionadas à pesquisa bibliográfica e documental, bem como as análises das ferramentas virtuais de comunicação do Parque Estadual da Ilha Grande (PEIG), foram iniciadas no primeiro semestre de 2016. Os dados obtidos foram sistematizados até dezembro do mesmo ano. A entrevista com o gestor $^{6}$ da área ocorreu somente em março de 2017 e também teve como intuito contextualizar como as ações de comunicação se inseriam no processo de gestão dessa área protegida. Para fins de delimitação de recorte temporal, todas as atualizações de informações referentes ao PEIG foram realizadas até o mês de julho daquele ano.

Tanto nas etapas de pesquisa, como no processo de construção deste artigo, foi considerado que a disseminação de informação sobre a importância da biodiversidade para a sociedade continua sendo reconhecida como uma questão global primordial. Nesse sentido, concordamos com Frome (1998), Carvalho (2009) e Dovers et al. (2015). Para essas referências as ações de comunicação sobre os temas ambientais têm relevância central para o êxito de políticas públicas. Para isso, devem ser consideradas particularidades socioculturais, entre outras especificidades das localidades onde se inserem.

Mas antes de iniciar a discussão sobre as principais questões observadas em relação às ações de comunicação dos dois parques estudados, considera-se importante resgatar, ainda que sinteticamente, algumas questões centrais que perpassam a trajetória da própria $\mathrm{CDB}$.

\footnotetext{
${ }^{4}$ Pesquisa possibilitada pelo Programa Doutorado-Sanduíche no Exterior (PDSE), financiado pela Coordenação de Aperfeiçoamento de Pessoal de Nível Superior (CAPES).

${ }^{5}$ Foram entrevistados o gestor do Parque, Enrico Giunta, e Elena Moutier que atuava, à época, com ações de comunicação e educação ambiental. ${ }^{6}$ Tercius Barradas.
} 


\subsection{Da Rio-92 às Metas de Aichi: avanços e desafios na implementação da $C D B$}

O Brasil e a Itália integram o grupo de 196 países que se tornaram signatários da $\mathrm{CDB}$, desde que a Convenção foi oficializada, em 1992, no âmbito da Conferência das Nações Unidas sobre Meio Ambiente e Desenvolvimento (CNUMAD). Esse evento emblemático realizado no Rio de Janeiro foi também denominado de Rio-92.

Alicerçada em três objetivos ${ }^{7}$, a CDB aumentou consideravelmente a ação pública global dirigida ao tema da conservação da biodiversidade, segundo Viola (1998). Nesse sentido, também tem inspirado diversas políticas públicas nos países signatários, desde 1993, quando entrou em vigor (Prates \& Irving, 2015).

Entretanto, mesmo que avanços em prol da agenda da conservação da biodiversidade tenham sido alcançados nas últimas duas décadas, motivados pela CDB, não se trata de um processo linear e homogêneo. Pelo contrário, é um processo que vem sendo perpassado por controvérsias, progressos e até mesmo retrocessos, de forma global (Irving \& Oliveira, 2012). Diante desse cenário, quais têm sido os principais caminhos trilhados rumo à implementação dessa Convenção?

Nesta retrospectiva, cabe destacar que, em 2002, dez anos após a realização da Rio-92, lideranças globais se reuniram durante a Cúpula de Desenvolvimento Sustentável da ONU, realizada na África do Sul, para avaliar os desdobramentos dos acordos assinados durante essa conferência emblemática. Neste novo encontro internacional, deno- minado de Rio +10 , os representantes dos diversos países membros da Organização das Nações Unidas (ONU) reconheceram a necessidade de ampliação de medidas de proteção da biodiversidade, questão refletida no documento final The Johannesburg Declaration on Sustainable Development (United Nations, 2002).

Reflexões semelhantes também tinham motivado novas ações no âmbito da própria $\mathrm{CDB}$, em 2002, meses antes da realização da Rio +10 . Naquele ano, os países signatários dessa Convenção se comprometeram a reduzir significativamente a taxa de perda de biodiversidade até 2010. Esse propósito foi inserido no Plano Estratégico 2002-2010, aprovado na $6^{a}$ Conferência das Partes da CDB (COP-6), realizada na Holanda, em 2002.

Porém, cumprido o prazo estabelecido no âmbito do planejamento mencionado, os resultados ficaram aquém das expectativas, segundo o relatório GBO3 (SCBD, 2010). Diante disso, os países signatários da $\mathrm{CDB}$ voltaram a se mobilizar. Assim, em 2010, durante a realização da $10^{a}$ Conferência das Partes da CDB (COP-10), em Nagoya, Japão, novos compromissos foram firmados para a década seguinte.

No contexto das deliberações centrais da COP10, foi definido o Plano Estratégico 2011-2020, ao qual se relacionam as denominadas Metas de Aichi. Esse pacto surpreendeu até mesmo o movimento ambientalista, uma vez que naquele período, o sentimento era de falta de perspectivas de avanços nas negociações (Oliveira \& Irving, 2011).

Muito embora os países signatários da CDB tenham assumido novos compromissos públicos

\footnotetext{
${ }^{7}$ Conservação e uso sustentável dos componentes da diversidade biológica (esses dois diretamente associados à temática deste artigo), além de repartição justa e equitativa dos benefícios gerados pelo uso dos recursos genéticos são os objetivos da CDB.
} 
dirigidos a essa agenda, ainda são inúmeros e complexos os desafios rumo ao alcance das 20 metas estabelecidas. Como partes centrais dos dilemas, destacam-se embates envolvendo medidas de conservação da biodiversidade versus demandas crescentes de exploração dos recursos naturais para sustentar o modelo de produção e consumo contemporâneo (UICN, WWF-Brasil, IPÊ, 2011).

Em continuidade a esta discussão, serão introduzidas, sinteticamente, a seguir, algumas das questões desafiadoras que emergem dessas reflexões sobre o alcance das Metas de Aichi. Para tal, o enfoque é direcionado à gestão de áreas protegidas e à inserção das ações de comunicação nesse contexto.

\subsection{Conservar a biodiversidade, para quêe} para quem? Uma breve leitura sobre as áreas protegidas no Brasil e na Itália

Conservar a biodiversidade significa proteger a multiplicidade de formas de vida existentes no planeta, por meio de ações de grande complexidade planejadas para uma escala de longo prazo (Wilson, 1997). Para tal, os órgãos ambientais, entre outras instâncias governamentais, tendem a adotar medidas que interferem diretamente na forma como diversos grupos sociais utilizam os recursos naturais. Como essa agenda envolve uma gama de atores sociais, com múltiplos interesses, a implementação de leis e outras formas de regulação são permeadas por tensões e controvérsias (Neves, 2012).

Nesse contexto regulatório, se insere o processo de criação, implementação e gestão de áreas protegidas, terminologia amplamente utilizada globalmente e que, particularmente no Brasil, é substituída em casos específicos pela denominação de unidade de conservação (UC) ${ }^{8}$, conforme ressalta Bensusan (2014). Apesar de reconhecida como uma das principais estratégias internacionais para a conservação da biodiversidade no longo prazo, sobretudo, no âmbito da CDB, a instituição de áreas protegidas tem motivado um amplo e controverso debate global uma vez que envolve a restrição de uso de recursos naturais (Giuliani, 2005; Irving, 2010).

Historicamente, diante da interpretação de que a ação da sociedade sobre a natureza é potencialmente destrutiva, se fortaleceu a ideia de reservar espaços naturais com a intenção de conservação de aspectos originais do planeta para alguns fins específicos. Entre estas finalidades estão a realização de pesquisas científicas e atividades de lazer e visitação. Os órgãos ambientais têm exercido o papel de controladores desses ambientes, o que tende a gerar resistências, já que as limitações de uso dos recursos naturais interferem nos modos de vida de populações que habitam o interior ou o entorno dessas áreas (Catão \& Carneiro, 2005).

Essa perspectiva de "blindagem" de algumas áreas de alta relevância ecológica dos efeitos da ação humana foi denominada por Diegues (1996) de o mito moderno da natureza intocada, título de uma de suas obras de referência. Na publicação, o autor apresenta um histórico do modelo de gestão de áreas protegidas disseminado mundialmente, sobretudo, a partir da criação do primeiro parque

\footnotetext{
8 “(...) espaço territorial e seus recursos ambientais, incluindo as águas jurisdicionais, com características naturais relevantes, legalmente instituído pelo Poder Público, com objetivos de conservação e limites definidos, sob regime especial de administração, ao qual se aplicam garantias adequadas de proteção." (Brasil, 2000, Artigo 2, Inciso I).
} 
nacional do mundo, o Yellowstone National Park, em 1872, nos Estados Unidos.

Seguindo uma tendência internacional, no Brasil as unidades de conservação criadas a partir da década de 1970 foram tradicionalmente orientadas pelo modelo de proteção integral. Isso impede o uso direto dos recursos naturais e a presença de ocupação humana, características fortemente expressas na categoria de parques. Já na década de 1990, em função das ações de mobilização social, houve uma abertura de espaço para a criação de UCs de uso sustentável. Nestas unidades, permite-se o uso direto dos recursos naturais de forma planejada e com visão de longo prazo (Giuliani, 2005; Irving, 2010).

No Brasil, os processos de criação, implementação e gestão de unidades de conservação (UCs) seguem os critérios e normas estabelecidos pelo Sistema Nacional de Unidades de Conservação da Natureza (SNUC), instituído pela Lei Federal $\mathrm{N}^{\circ}$ 9.985/ 2000 (Brasil, 2000). No âmbito desse arcabouço legal, as UCs federais, estaduais e municipais estão distribuídas em categorias de manejo de proteção integral ${ }^{9}$ e de uso sustentável ${ }^{10}$. Somando ambas as tipologias, o país contava com 2.082 UCs na área continental, ocupando uma superfície de 1.535.127 quilômetros quadrados; além de 169 UCs na área marinha, ocupando 55.200 quilômetros quadrados, até julho de $2017^{11}$. Este total estava distribuído da seguinte forma nos biomas brasileiros: Amazônia, 27,3\%; Caatinga, 7,7\%; Cerrado, 8,3\%; Mata Atlântica, 9,4\%; Pampa, 2,8\%; Pantanal, 4,6\% e área marinha, $1,6 \%$.

Em contrapartida, ainda que inserida em um contexto geográfico, político e socioeconômico diferente da América Latina, a política dirigida às áreas protegidas da Itália parece ter evoluído na mesma direção das estratégias brasileiras, pela ótica de Giuliani (2005). Segundo o autor mencionado, até a década de 1980, esse tipo de iniciativa estava fortemente voltado ao enfrentamento do risco de extinção de determinadas espécies de animais e vegetais naquele país da União Europeia. Contudo, uma reestruturação no sistema italiano, no início da década de 1990, passou a reconhecer não somente o papel das áreas protegidas para a conservação da biodiversidade, mas, também, a relevância desses espaços como indutores de desenvolvimento local.

Com base em informações do Ministério do Ambiente e da Tutela do Território e do Mar $(\text { MATTM })^{12}$, o Sistema Nacional de Áreas Protegidas da Itália ${ }^{13}$ (ancorado na Lei $N^{\circ}$. 394/1991) responde pela gestão de 871 áreas protegidas que abrangem 3,1 milhões de hectares terrestres (10,5\% do território nacional). As 27 áreas prote-

\footnotetext{
${ }^{9}$ Categorias de manejo de UCs de proteção integral: Estação Ecológica, Reserva Biológica, Parque Nacional, Monumento Natural e Refúgio de Vida Silvestre.

${ }^{10}$ Categorias de manejo de UCs de uso sustentável: Área de Proteção Ambiental, Área de Relevante Interesse Ecológico, Floresta Nacional, Reserva Extrativista, Reserva de Fauna, Reserva de Desenvolvimento Sustentável e Reserva Particular do Patrimônio Natural.

Fonte: <http://www.mma.gov.br/areas-protegidas/unidades-de-conservacao/categorias>. Acesso em: jan.2017.

${ }^{11}$ Fonte: <http://www.mma.gov.br/images/arquivo/80112/CNUC_JUL17\%20-\%20C_Bio.pdf>. Acesso em: jul.2017.

${ }^{12}$ Fonte: <http://www.naturaitalia.it/areeNaturaliProtette.do $>$. Acesso em: jan.2017.

${ }^{13}$ O Sistema italiano é constituído das seguintes categorias de manejo: Parque Nacional, Parque Natural Regional, Reserva Natural, Áreas Protegidas Marinhas, Zonas Úmidas de Importância Internacional (Ramsar) e Outras Áreas Naturais Protegidas.
} 
gidas marinhas nacionais, somadas a um Santuário Internacional de Mamíferos Marinhos (2,5 milhões de hectares), totalizam 2,8 milhões de hectares. A área costeira protegida, por sua vez, é de 658 quilômetros.

Segundo Pellizzaro et al. (2015), globalmente não parece haver ampla correspondência entre os padrões estabelecidos pelos países e o sistema internacional de classificação de áreas protegidas, proposto pela IUCN (1994). De acordo com um levantamento realizado pelos autores mencionados, em países de cinco continentes, incluindo o Brasil e a Itália, a única exceção se refere à categoria Parque Nacional (encontrada em todos os países pesquisados).

Por outro lado, ainda que uma organização ambientalista com grande poder de influência como a IUCN não tenha sido capaz de orientar um sistema global equivalente de classificação de áreas protegidas - com enfoque no fortalecimento de uma linguagem comum nas formas de categorização desses espaços -, alguns autores como Pellizzaro et al. (2015) consideram que diversos avanços conceituais têm sido mais amplamente aceitos mundialmente. Para as referências mencionadas, o reconhecimento da importância de integração de valores culturais das localidades aos mecanismos de conservação dos recursos naturais é parte desse processo de avanços.

Conforme também assinalam Fernandes-Pinto \& Irving (2017), uma mudança paradigmática nesse sentido ocorreu durante a realização do $V$ Congresso Mundial de Parques ${ }^{14}$. $\mathrm{O}$ evento foi considerado um marco para esse debate, por ter trazido recomendações sobre a importância da integração dos valores culturais aos processos de gestão de áreas protegidas globalmente.

Assim, embora a criação de áreas protegidas seja reconhecida pela importância estratégica para a conservação da biodiversidade global, essa temática envolve grande complexidade. Nesse sentido, buscou-se discutir, ainda que sinteticamente, algumas das questões desafiadoras que perpassam essa agenda. Lançar tais reflexões tende a ser fundamental para introduzir, a seguir, a discussão sobre as interfaces da comunicação no processo de gestão de áreas protegidas, principal motivação deste artigo.

\subsection{A comunicação como elemento central ao êxito das diretrizes da $C D B$}

Sensibilizar a sociedade sobre a importância da conservação e do uso sustentável da biodiversidade é considerada uma questão central ao êxito das ações planejadas pelos signatários da CDB. Com esse propósito, o artigo 13 sobre Educação e Conscientização Pública da Convenção orienta que os países devem estimular a compreensão dessa temática. Isso deve ser feito por intermédio da divulgação de informações na mídia e da implementação de programas educacionais.

O Programa de Trabalho sobre Comunicação, Educação e Consciência Pública (CEPA ${ }^{15}$, na sigla em inglês) constitui um dos principais eixos deste direcionamento da CDB. Para promover o fortalecimento dessa temática, foi elaborada durante

\footnotetext{
${ }^{14}$ Evento realizado em Durban, África do Sul, em 2003. Os congressos mundiais de parques são promovidos pela IUCN desde 1962 (uma vez a cada década) e apresentam importantes deliberações que orientam os processos de gestão de áreas protegidas globalmente.

${ }^{15}$ Informações sobre a CEPA disponíveis em: <http://www.cepatoolkit.org/>. Acesso em: jan.2016.
} 
a COP-8 (sediada no Brasil, em 2006) uma lista de prioridades no contexto dessa iniciativa. Foi elencada a necessidade de realização de oficinas de capacitação regionais e sugerida a organização de um guia para facilitar a aplicabilidade das práticas de comunicação sobre o tema globalmente.

Com base nas prioridades definidas, o Secretariado da $C D B$ solicitou à União Internacional para a Conservação da Natureza (IUCN) que desenvolvesse a denominada caixa de ferramentas para a $\mathrm{CEPA}^{16}$. Dirigido aos tomadores de decisão nos países signatários da Convenção, esse guia com versões em Inglês e Espanhol busca orientar as iniciativas governamentais e não governamentais de comunicação e educação sobre a agenda da conservação da biodiversidade, por meio de uma ampla sistematização de informações especializadas.

Para Hesselink et al. (2007), organizadores da publicação mencionada, um dos grandes desafios dos países signatários da CDB é justamente o desenvolvimento de ações de Comunicação, Educação e Consciência Pública. Nos processos de gestão de áreas protegidas, as recomendações desse guia tendem a ser fundamentais já que parte de seus objetivos é justamente apresentar a ampla gama de recursos comunicativos. Esses recursos podem ser utilizados em prol da disseminação de informação para a sociedade sobre a importância desses espaços para a conservação da biodiversidade.

Nesse contexto, há de se ressaltar, também, as recomendações de Hamú et al. (2004) que destacam a importância das ações de comunicação para o alcance dos objetivos de conservação e uso sustentável da biodiversidade em áreas protegidas.
Para tal, essas iniciativas devem ser consideradas transversalmente nos processos de gestão desses espaços, tendo em vista questões socioculturais e outras dimensões que envolvem a gama de atores sociais que se deseja informar e engajar. No entanto, concretizar essas orientações ainda representa um desafio, como se discute a seguir.

\section{Parque Estadual da Ilha Grande e sua relevância para a conservação da biodiversidade no Rio de Janeiro}

Criado na década de $1970^{17}$, com o objetivo de resguardar um patrimônio ambiental inestimável em território fluminense, o Parque Estadual da Ilha Grande (PEIG) está localizado no município de Angra dos Reis, litoral sul do Estado do Rio de Janeiro. Essa região é conhecida mundialmente, tanto pela beleza das suas paisagens como pela grande diversidade dos seus ecossistemas naturais formados por florestas, praias, restingas e manguezais, além de córregos, costões rochosos e outros.

Devido à sua importância ecológica e localização estratégica para a conservação da biodiversidade, o PEIG foi reconhecido como Reserva da Biosfera da Mata Atlântica, em 1992, pela Organização das Nações Unidas para a Educação, a Ciência e a Cultura (UNESCO). Desde então, ganhou status internacional no contexto das políticas públicas de proteção da natureza (INEA, 2011; 2013).

O PEIG ocupa 12.052 hectares e abrange $62,5 \%$ da área terrestre da Baía da Ilha Grande (BIG) que é formada pelos municípios de Angra

\footnotetext{
${ }^{16}$ Disponível em: <https://www.cbd.int/cepa/toolkit/2008/doc/CBD-Toolkit-Complete.pdf>. Acesso em: jun.2016.

${ }^{17}$ Criado pelo Decreto Estadual No 15.273 , de 26 de junho de 1971.
} 
dos Reis, Paraty e Mangaratiba e considerada a baía mais preservada do Estado do Rio de Janeiro. Pela localização geográfica privilegiada, a interface física dessa área protegida mantém ampla conectividade com o entorno marinho. Isso the confere um importante diferencial paisagístico e ecossistêmico em uma região em que a pesca e o turismo representam algumas das principais atividades econômicas (INEA, 2011).

A região da $\mathrm{BIG}$, na qual o $\mathrm{PEIG}$ se insere, é reconhecida com hotspot, ou seja, é uma área de biodiversidade significativa e, ao mesmo tempo, fortemente pressionada por ameaças de degradação. Por abrigar os principais remanescentes florestais de Mata Atlântica do Estado Rio de Janeiro, a criação de áreas protegidas se tornou uma iniciativa estratégica para a conservação da biodiversidade ainda existente na região dessa baía. Nesse sentido, o PEIG também é parte do Mosaico Bocaina, formado por 18 unidades de conservação, cinco terras indígenas e quatro territórios quilombolas localizados entre o Rio de Janeiro e São Paulo, com objetivo de fortalecer a gestão integrada desses espaços de rica diversidade ambiental e cultural.

Dentre os principais objetivos do Parque Estadual da Ilha Grande se destacam a preservação dos ecossistemas naturais; a realização de pesquisas científicas; além das atividades de educação e interpretação ambiental, recreação e turismo ecológico. Para tal, nesta área protegida há um Centro de Visitantes que dispõe de materiais educativos e serviços de visitas guiadas para estudantes. Como opções de uso público se destacam atividades como trilhas, banhos em cachoeiras, mergulhos, visitas contemplativas e montanhismo. Entretanto, o parque também enfrenta problemas como a visitação por acessos não autorizados e o comportamento predatório de visitantes em áreas remotas; além de outros impactos negativos, como a extração ilegal de plantas e a caça de animais silvestres (INEA, 2011).

As ameaças à conservação da biodiversidade, mencionadas anteriormente, se ampliaram a partir da década de 1960, quando a região passou a ser fortemente pressionada pela especulação imobiliária. Esse processo foi impulsionado por sua atratividade natural e pela facilidade de acesso de visitantes de grandes centros urbanos, como Rio de Janeiro e São Paulo, principais capitais do país (Vallejo, 2005b).

A valorização da região na qual o Parque Estadual da Ilha Grande se insere passou a provocar também inúmeros impactos socioculturais, como a desagregação de modos de vida ancestrais. Nesse contexto, populações como as de pescadores que tradicionalmente estavam estabelecidas naquelas praias foram levadas a habitar morros e encostas da Serra da Bocaina, estimulando, assim, o processo de favelização (Diegues \& Nogara, 2005).

Em meio às pressões advindas do crescimento urbano e industrial, bem como da falta de infraestrutura de serviços públicos como saneamento e outros, a expansão desordenada das atividades turísticas foi provocando, ao longo de décadas, o aumento da degradação da BIG e causando preocupações devido à grande relevância ecológica da região (Alho, 2002; INEA, 2011).

Devido à ampliação do debate público sobre os impactos negativos decorrentes do turismo de massa na BIG, algumas soluções de enfrentamento desse processo vêm sendo cogitadas nos últimos anos. Uma alternativa já divulgada por veículos de circulação nacional, porém considerada controversa, se refere à perspectiva de cobrança de taxa para a entrada de visitantes na Baía da Ilha Grande. Os 
recursos arrecadados seriam investidos em ações de proteção ambiental (Araújo, 2015).

Como forma de enfrentamento de pressões provocadas pelo turismo de massa, vem sendo cogitada ainda a proposta de Parceria Público-Privada (PPP) como um possível modelo de gestão para o PEIG. Esse é outro tema controverso. Diversas organizações da sociedade civil se opõem à aliança entre governo e iniciativa privada, por considerarem que a gestão de recursos naturais estratégicos deve ser mantida na esfera do poder público (Garcia, 2016).

De maneira geral, pode-se afirmar que os riscos associados ao avanço do interesse turístico na Baía da Ilha Grande são percebidos pelas populações locais, como analisa Oliveira (2008). Ainda assim, segundo observado pela autora, contraditoriamente, moradores da região não interpretam uma tendência de sustentabilidade no modelo de turismo local, nem mesmo o praticado no âmbito da gestão do PEIG. De acordo com a mesma referência, a falta de disseminação de informações sobre as normas e leis ambientais, nas quais se apoiam a existência de áreas protegidas como o PEIG, constitui um problema que afeta a percepção dos moradores sobre esse modelo de regulação do uso dos recursos naturais. A autora identificou também junto a esses interlocutores um sentimento de distanciamento do processo de proteção da natureza instituído no contexto da gestão do parque.

Diante dessas percepções, torna-se ainda mais ilustrativo o grande desafio que representa a ampliação de ações educativas e de disseminação de informação sobre o PEIG, não somente para os turistas, mas principalmente para os moradores da Baía da Ilha Grande. Além disso, considerando que a Meta 1 de Aichi tende a motivar a reflexão sobre os desafios que se impõem ao processo de ampliação da disseminação de informação sobre a conservação da biodiversidade, em que medida essas ações têm sido fortalecidas no âmbito da gestão do PEIG, atualmente? Essa é uma questão que perpassa a discussão apresentada a seguir.

\subsection{Comunicação no Parque Estadual da Ilha Grande, dilemas e potenciais}

No contexto desta investigação, uma das primeiras constatações foi de que o PEIG não contava com um website exclusivo no período dedicado à pesquisa das ferramentas online disponíveis. O conteúdo informativo oficial sobre o parque vinha sendo apresentado em uma página inserida no website do Instituto Estadual do Ambiente (INEA) ${ }^{18}$, órgão ambiental responsável pela gestão das unidades de conservação do Estado do Rio de Janeiro.

O website do INEA era, até então, o principal canal de comunicação oficial sobre o PEIG para a sociedade. Durante a análise neste espaço virtual, foi possível perceber duas características centrais. A apresentação de conteúdo informativo da página analisada, além de resumida, dava ênfase ao processo de criação do parque, dentre outras abordagens de caráter mais documental. Em uma das poucas mensagens mais diretas para o público, foi possível observar que a comunicação, em geral, se referia às orientações sobre o comportamento esperado de visitantes em uma área protegida. A ênfase, neste caso, era voltada ao respeito à biodiversidade e aos cuidados durante atividades esportivas. Um peque-

\footnotetext{
${ }^{18}$ Conteúdo disponível em: <http://200.20.53.3:8081/Portal/index.htm>. Acesso em: jul.2016.
} 
no folheto com essa abordagem estava disponível no espaço de apresentação da localização do parque.

Como partes do conteúdo informativo sobre o PEIG, apresentado no âmbito do website pesquisado, se destacavam, ainda, um mapa e uma versão na íntegra do Plano de Manejo (INEA, 2011) ${ }^{19}$. Esse documento estabelece normas e restrições de uso, além de orientar sobre as ações de gestão dos recursos naturais nas unidades de conservação. Da mesma forma, estavam disponíveis informações sobre o Conselho Consultivo do parque, incluindo a sua composição. Já a parte final do conteúdo disponibilizado no website apresentava, até então, informações sobre como devem ser desenvolvidas as atividades de pesquisa científica no parque e sobre os estudos em andamento.

Além do espaço virtual inserido no website oficial do INEA, o PEIG contava, também, com uma página no Facebook $^{20}$, com 8,8 mil seguidores. Os principais conteúdos disseminados na rede social incluíam notícias e fotografias sobre eventos realizados desde 2010. Diferentemente do conteúdo pouco ilustrado do website analisado, apresentado anteriormente, nesta rede social centenas de imagens compartilhadas pelos internautas e pelos profissionais do parque mostravam momentos de interação entre visitantes e o ambiente dessa área protegida.

A maior parte das notícias postadas na página do PEIG no Facebook informava sobre atividades que vinham sendo realizadas com enfoque na conservação da biodiversidade da região de inserção do parque. Essa ênfase vinha sendo apresentada, por exemplo, a partir de edições do Vem Passarinhar Rio - Parque Estadual da Ilha Grande. Esse evento é realizado anualmente e destinado à observação de pássaros por moradores, turistas e ambientalistas. Conforme analisado, os internautas costumavam compartilhar os seus registros fotográficos nessa rede social.

Outros assuntos divulgados pelo Facebook e identificados nesta análise envolviam, ainda, as atividades do Conselho Consultivo do PEIG, além de notícias sobre palestras, distribuições de mudas de árvores daquela região e outras ações educativas voltadas para os moradores.

No entanto, foi possível perceber que, apesar de parecer mais dinâmica em relação à página oficial do PEIG, inserida no website pesquisado, a página do parque no Facebook também carecia de atualização. Nesse sentido, foi verificada a ocorrência de meses de intervalo entre algumas postagens. Ou seja, o conteúdo, por vezes, tendia a estar defasado.

Diante dessas e de outras limitações existentes, como avançar para que o acesso à informação qualificada sobre o PEIG seja garantido? Como assegurar que as ações de comunicação sejam potencializadas no processo de gestão desse parque, de forma que a sua importância para a conservação da biodiversidade tenha mais possibilidades de ser amplamente disseminada para a sociedade, como orientado pela Meta 1 de Aichi? O que pensam os interlocutores atuantes no parque sobre o tema discutido neste artigo?

Segundo ressaltado pelo gestor do PEIG, durante entrevista, o desenvolvimento de ações de

\footnotetext{
${ }^{19}$ Plano de Manejo disponível em: <http://www.inea.rj.gov.br/cs/groups/public/documents/document/zwew/mdiw/ edisp/inea0020167.pdf> . Acesso em: jul.2016.

${ }^{20}$ Disponível em: <https://www.facebook.com/Parque-Estadual-da-Ilha-Grande-278015802756/>. Acesso em: jul.2016.
} 
comunicação é considerado como prática fundamental no cotidiano da área protegida ${ }^{21}$. Nesse sentido, ainda que os obstáculos para o alcance desse objetivo específico fossem reconhecidos, havia um processo de avanços em andamento. Conforme adiantado por esse interlocutor, um novo website para disseminação de informações mais detalhadas sobre os parques do Estado do Rio de Janeiro, entre eles o PEIG, estava em fase final de elaboração.

Além de buscar inovar na forma de apresentação dos conteúdos a partir do website que vinha sendo elaborado, também estava nos planos do órgão gestor a atualização frequente da página do PEIG no Facebook. Essa rede social é considerada pela equipe de gestão como fundamental à disseminação de notícias sobre o parque. A ferramenta também é reconhecida como um espaço essencial à facilitação do processo de interatividade entre os gestores e a sociedade.

Sobre o fortalecimento das ações de comunicação do PEIG não somente para os turistas, mas para os moradores da região, a equipe de gestão do parque considera que questões estruturais, como a falta de energia elétrica em algumas comunidades da Baía da Ilha Grande, são alguns dos principais obstáculos a superar. Cabe ressaltar que, nesse caso, como o problema dificulta a conexão local com os sistemas de telefonia e internet, outras estratégias de interação e de divulgação de informação precisam ser pensadas especificamente para atender a esse tipo de público. A realização de oficinas temáticas, palestras e rodas de diálogo, entre outros eventos presenciais, além da distribuição de materiais im- pressos são algumas alternativas que poderiam ser úteis nesse sentido. Outras ações também devem ser pensadas com o intuito de identificar demandas, principalmente, junto a esses e outros grupos de moradores da região. Nessa perspectiva, poderão ser planejadas soluções que busquem apreender, pelo ponto de vista local, aspirações em relação às práticas de disseminação de informação, com enfoque na agenda de conservação da biodiversidade. Tal estratégia tende, inclusive, a aproximar os residentes e as equipes de gestão do parque.

Ainda como parte dos desafios enfrentados pela equipe de gestão do PEIG, ressaltados durante entrevista, o turismo predatório na Baía da Ilha Grande é considerado como o maior problema a ser superado. Esse fator de pressão tem causando preocupações, sobretudo, em relação à capacidade de suporte das áreas que compõem essa região de grande interesse turístico, na qual o parque se insere.

Diante desse cenário, ao longo dos últimos anos o INEA vem promovendo ações de comunicação como caminhos para a sensibilização de moradores e turistas sobre as principais questões ambientais relacionadas ao parque. O objetivo é minimizar os impactos negativos decorrentes da visitação desordenada na região. Tais práticas, no entanto, tendem a alcançar maior êxito com o apoio de ferramentas de comunicação que estejam funcionando plenamente e de outras estratégias com esse objetivo, adaptadas às especificidades de público que se deseja envolver.

Nesse sentido, podem ser úteis as orientações $^{22}$ de disseminação de informação qualificada

\footnotetext{
${ }^{21} \mathrm{O}$ contexto da comunicação foi apresentado em entrevista com o gestor do PEIG, Tercius Barradas, em março de 2017, já que não havia referência no website oficial sobe a inserção desse componente no processo de gestão dessa área protegida, apesar de reconhecida a sua importância como destacado pelo entrevistado.

${ }^{22}$ Um guia sobre o tema está disponível em: <www.cbd.int/sp>. Acesso em: abr.2017.
} 
sobre a agenda da conservação da biodiversidade, elaboradas por especialistas em comunicação ambiental. Estas diretrizes estão disponíveis em um guia online e devem ser apropriadas pelos órgãos de gestão pública e movimentos sociais, pela academia e por outros segmentos da sociedade, para que se possa avançar nesse tipo de estratégia. Assim, esse conteúdo tende a ser mais um facilitador para o alinhamento dos tomadores de decisão com as Metas de Aichi, com ênfase na Meta 1, que inspira esse artigo.

No Brasil, também já foi elaborada a Estratégia Nacional de Comunicação e Educação Ambiental em Unidades de Conservação (ENCEA) ${ }^{23}$. Seu objetivo é orientar a implementação de melhores práticas sobre essa temática em políticas públicas e outras ações dirigidas às unidades de conservação, tais como as que se expressam como demandas no contexto do PEIG.

\subsection{Conclusões}

Em linhas gerais, a partir da análise da página oficial do PEIG, inserida no website do órgão gestor, foi possível perceber que havia, até então, falta de dinâmica no conteúdo informativo apresentado. Além de observada a ausência de espaço destinado à inserção de notícias atualizadas, não foram visualizadas fotografias diversificadas que pudessem ilustrar tanto a beleza cênica do parque, como exemplos de interação de seus visitantes com os ambientes naturais abertos ao público. Tampouco havia destaque sobre a relevância de sua biodiversidade. Para se acessar esse tipo de conteúdo, era preciso abrir documentos técnicos como o Plano de Manejo, cujos links estavam disponíveis.

Ainda em relação à página pesquisada no website mencionado, não foram identificadas mensagens mais diretas, de convite aos internautas, para conhecerem o parque e desfrutarem de seus ambientes diversificados. Embora atividades educativas estivessem sendo desenvolvidas com intuito de apresentar ao público informações sobre a importância de conservar esse patrimônio no longo prazo, conforme ressaltado anteriormente, essas práticas não vinham sendo destacadas nesse espaço virtual disponível.

Da mesma forma, na página analisada não foram visualizadas, até então, informações sobre a realização de eventos destinados aos visitantes desse parque, considerado de importância central para a conservação da biodiversidade no litoral do Estado do Rio de Janeiro.

Além disso, no contexto da análise realizada, não se observou a integração das duas plataformas oficiais de informação sobre o PEIG disponíveis via internet. Nesse sentido, no website não foi visualizada qualquer referência à existência da página do parque no Facebook. Nesta rede social, por sua vez, não havia um link que pudesse direcionar os internautas para o canal oficial de comunicação online.

Considerando que o PEIG recebe cerca de 800 mil visitantes por ano ${ }^{24}$, com canais de comunicação atualizados e integrados, esse tende a ser um público com grande potencial para compartilhamento de informações disseminadas junto às suas redes. Este tipo de movimento é cada vez mais facilitado pelos avanços das mídias digitais.

\footnotetext{
${ }^{23}$ Ver as diretrizes da ENCEA em: <http://www.icmbio.gov.br/educacaoambiental/politicas/encea.html>. Acesso em: jul.2017.

${ }^{24}$ Segundo informado durante entrevista realizada com o gestor, Tercius Barradas, em março de 2017.
} 
Da mesma forma, seria recomendável que as ações sobre o PEIG pudessem adquirir maior visibilidade à medida que fossem divulgadas na mídia, em geral, e também reproduzidas nos espaços oficiais de disseminação de informações da gestão pública.

Em continuidade a esse debate, nas páginas a seguir são apresentadas as principais ações de comunicação desenvolvidas no âmbito da gestão do Parque Natural da Maremma e as análises sobre o tema produzidas no contexto desta pesquisa.

\section{Parque Natural da Maremma, a área protegida mais antiga da Toscana}

Com quatro décadas de criação, celebradas em 2015, o Parque Natural da Maremma configura-se como a área protegida mais antiga da Toscana ${ }^{25}$. É reconhecido pela riqueza em biodiversidade, pela beleza cênica (descortinada ao longo de 25 quilômetros de costa) e, também, por seu papel como vetor de desenvolvimento socioeconômico na região onde está inserido.

O território do parque totaliza 9.800 hectares que abrangem desde a foz do rio Ombrone até Talamone, na província de Grosseto. Essa região é cortada por uma cadeia de montanhas que se estende em direção ao mar Tirreno. Nesse contexto geográfico de ecossistemas diversificados, envolvendo praias e falésias, pântanos e florestas, além de um rico patrimônio histórico-cultural, o parque atrai, anualmente, cerca de 50 mil visitantes pagantes ${ }^{26}$.
Vale ressaltar que toda a região costeira italiana, na qual o parque se insere, se destaca pela forte vocação turística. Para além das discussões sobre os potenciais impactos desse segmento nas dimensões ambientais e culturais, também tem existido um esforço investigativo de interpretação dos conflitos que costumam emergir da relação entre residentes e turistas. Bimonte \& Punzo (2011) e Bimonte \& Faralla (2012) já desenvolveram estudos com esse enfoque.

Por outro lado, a região de inserção dessa área protegida também é marcada pela forte tradição na produção agropastoril, com ênfase no cultivo de oliveiras para a extração de azeite e de pastagens para a criação de pequenos rebanhos. Esse perfil é ressaltado em uma publicação oficial que discute os avanços e os desafios para a gestão de áreas protegidas da Toscana. Nesse contexto, é discutida ainda a relevância de conciliação dos objetivos de pesquisa científica e de proteção dos recursos naturais e culturais do Parque da Maremma, de forma a aproveitar o seu potencial como indutor de desenvolvimento social e econômico regional a longo prazo (Regione Toscana, 2009, p. 40).

Nesta perspectiva de conciliação dos objetivos de conservação da natureza e de estímulo às vocações socioeconômicas regionais (nas quais se inserem a visitação turística), foram destacados por Venturi (2015), no contexto das celebrações dos 40 anos do parque, alguns projetos considerados, até então, importantes para a sua gestão. Entre eles, a conclusão da reintrodução do falcão-pescador

\footnotetext{
${ }^{25}$ Instituído em 5 de junho de 1975, pela Lei no 65 da Região Toscana.

${ }^{26}$ Informação fornecida pelo diretor Enrico Giunta, em entrevista realizada pessoalmente, durante visita ao parque em 2015 . Nessa oportunidade, foram reiterados aspectos relacionados à importância da comunicação no sistema de gestão dessa área protegida, questão também mencionada em conteúdo do website oficial pesquisado.
} 
(Pandion haliaetus). Essa espécie esteve ausente da região por cerca de 40 anos. Mais recentemente, no entanto, o falcão-pescador vinha se reproduzindo em zonas úmidas protegidas e atraindo a atenção tanto de visitantes como de pesquisadores.

Para que se possa compreender o contexto de gestão do parque pesquisado, na atualidade, é importante conhecer os motivos que levaram à criação dessa área protegida. Segundo retrospectiva de Bimonte \& Pagni (2003), o poder público precisou frear o processo de especulação imobiliária que ganhava força nessa região, na década de 1970.

Como resultado da criação dessa área protegida, segundo os autores mencionados, de 1975 a 1998, o território do parque foi fortemente administrado por meio de regras e restrições de uso. Nesse período, houve a necessidade de controle mais rigoroso no processo de gestão, em função de pressões relacionadas ao desenvolvimento urbano e às ameaças associadas ao turismo de massa. Tais medidas alimentaram tensões entre a população, representantes das instuições locais e a administração do parque.

Em busca de um novo modelo de gestão capaz de conciliar objetivos de conservação dos recursos naturais com melhores práticas de desenvolvimento regional, ocorreu uma transição a partir de 1994. Saiu-se de uma situação de forte regulação pela administração da área protegida para uma fase de mais aproximação entre os gestores públicos e os atores locais (Bimonte \& Pagni, 2003).

Assim, com mais abertura para o diálogo, um dos avanços percebidos foi o de incentivo às atividades complementares de produção agrícola para as fazendas da região. Diante desse processo, se inicialmente, a percepção dos habitantes da região era de que a criação do parque representava um risco de possível desvalorização dos seus imóveis, em uma etapa posterior, a presença da área protegida passou a ser reconhecida como um elemento agregador de valor. Para Bimonte \& Pagni (2003), essa percepção positiva transcendeu a leitura dos moradores da área, uma vez que essa marca do território alcançou reconhecimento regional.

Frente à conjuntura mais favorável ao diálogo e à busca de soluções conjuntas, a década seguinte contribuiu para a construção de diretrizes com enfoque na qualidade da gestão dessa área protegida. Essas orientações, por sua vez, se refletiram nas dinâmicas econômicas regionais.

Desta forma, além de ter sido o primeiro parque criado na Toscana, o Parque da Maremma também foi pioneiro na região a orientar a administração pelo sistema de gestão ambiental internacional ISO 14000, em 2003 (Regione Toscana, 2009). Desde então, as práticas de gestão dessa área protegida têm passado por revisões periódicas para efeito de renovação do selo verde.

A qualificação em gestão ambiental buscou incentivar o entorno. Esse processo foi baseado, principalmente, em um guia de orientação para estabelecimentos hoteleiros rumo à melhoria da qualidade dos serviços oferecidos aos turistas e à redução dos impactos ambientais decorrentes de suas atividades. Nesse contexto, a disseminação de informações sobre a importância do parque e sobre os benefícios oriundos da sua área de influência também foi considerada como elemento fundamental.

Ademais, para a administração do parque, o projeto de gestão ambiental também oferece a oportunidade de intercâmbio contínuo de informação entre a equipe de gestão e os empreendedores turísticos da região. Essa experiência tem permitido o aperfeiçoamento de estratégias de incentivo à 
visitação nessa área protegida. As ações de comunicação, discutidas mais amplamente a seguir, são consideradas como elementos centrais ao êxito dessa iniciativa, conforme reiterado pelos interlocutores entrevistados.

\subsection{Estratégia de comunicação como elemento fundamental para a integração com a sociedade}

O website oficial do Parque da Maremma ${ }^{27}$ tem sido considerado o principal veículo de disseminação de informação sobre a importância dessa área protegida para o público em geral. Nesse espaço virtual, criado há uma década, são divulgadas as características ambientais mais relevantes e as melhores práticas de gestão desse patrimônio toscano, além de atualizadas notícias sobre as diversas atividades socioculturais realizadas na área ao longo do ano. O conteúdo informativo é apresentado em dois idiomas (Italiano e Inglês).

Observa-se, ao analisar o conjunto de informações do website, subdividido em quatro partes denominadas Conheça, Viva, Participe e Estude, que esta iniciativa parece traduzir com clareza a intenção de motivar o interesse do público para o usufruto dos espaços do parque. Essa motivação se reflete nos destaques para o que há de mais importante em termos de patrimônios natural, histórico e cultural.

Na seção Conheça, foi possível observar a contextualização de informações gerais sobre fatos históricos e lendas que envolvem a região do parque, além de curiosidades sobre monumentos arquitetônicos, características da flora e da fauna e descobertas arqueológicas existentes na sua área de influência.

Por meio da seção Viva, os visitantes vinham sendo convidados a conhecerem o parque a partir de informações sobre os principais itinerários e atividades culturais e de educação ambiental. Nesse contexto, havia indicação dos estabelecimentos de hospedagem e alimentação alinhados aos critérios de gestão ambiental orientados pela administração. Um mapa da região concentrava os principais dados (endereço, telefone e website) dos empreendimentos com o selo verde. O conteúdo dessa seção oferecia ainda vários links para acesso aos portais de instituições ambientais regionais, nacionais e internacionais, dentre os quais, o da Federação Italiana de Parques e Reservas Naturais (Federparchi). Sendo assim, também parecia clara a intenção de facilitação de interconexão dos internautas a um universo mais amplo de acesso à informação sobre a agenda de conservação da biodiversidade em diversos níveis de gestão, por meio desse espaço virtual.

Já na seção Participe, foi possível perceber que os internautas vinham sendo incentivados a se inscreverem no Concurso Fotográfico As Estações no Parque ${ }^{28}$. Havia destaque para paisagens, espécies de animais e de plantas, assim como fotos que expressavam a satisfação dos turistas que já mantiveram contato com aquele ambiente natural. Dessa forma, o conteúdo referente a esta premiação sinalizava uma motivação permanente de usufruto dos benefícios socioambientais e culturais dessa área protegida.

\footnotetext{
${ }^{27}$ Disponível em: <http://www.parco-maremma.it/>. Acesso em: jul.2016.

${ }^{28}$ Saiba mais em: <http://www.parco-maremma.it/partecipa/concorso-fotografico/>. Acesso em: jan.2017.
} 
Por outro lado, na seção Estude, observou-se uma orientação para que estudiosos interessados em pesquisar no parque ou conhecer o resultado de trabalhos científicos realizados pudessem encontrar informações específicas.

Um calendário anual continha imagens que destacavam a biodiversidade e as paisagens naturais do parque, para cada mês do ano. Isso parecia ilustrar como alternativas simples podem ter uma função pedagógica no contexto de um conjunto de ferramentas de comunicação integradas.

Nesta análise, percebeu-se, ainda, que o website também se destinava a apresentar a instituição responsável pela gestão do parque e sua forma de atuação, conforme orientação da normativa italiana de administração transparente ${ }^{29}$.

Ainda que representasse o principal espaço oficial de disseminação de informação do Parque da Maremma para a sociedade, conforme observado no contexto desta pesquisa, o website não era o único canal disponível. Nesse sentido, os gestores da área protegida já vinham buscando ampliar a sua visibilidade via internet por reconhecerem o potencial das redes sociais como ferramentas de comunicação. Para tal, foi criada inicialmente uma página no Facebook ${ }^{30}$.

Em julho de 2017, a página no Facebook contava com mais de 11 mil seguidores. As informações sobre as atividades abertas ao público vinham sendo atualizadas frequentemente, além de compartilhadas as notícias sobre o parque divulgadas nos meios de comunicação italianos e internacionais. Entretanto, observou-se que o enfoque na maior parte das postagens era de incentivo ao turismo nessa área protegida.

Informações sobre o parque também vinham sendo divulgadas em outras três redes sociais: Intagram, Youtube e Pinterest. Todas integradas entre si. O Instagram ${ }^{31}$, ambiente virtual dedicado principalmente à postagem de fotografias, contava com 1,2 mil seguidores e mais de 200 imagens divulgadas. Nessa página, os internautas vinham sendo incentivados a compartilharem experiências de contato com a natureza dessa área protegida.

Mas, tanto o Youtube 32 (canal online de vídeos), como o Pinterest $^{33}$ (rede social de compartilhamento de fotografias e vídeos) pareciam ser mídias sociais ainda pouco difundidas no conjunto de ferramentas de comunicação usado para disseminar informações sobre a área protegida pesquisada. Nessas redes mencionadas, foram identificados, respectivamente, 40 inscritos e doze seguidores, até julho de 2017. Os dois espaços virtuais apresentavam como principais enfoques a beleza das paisagens e a diversidade de fauna e flora desfrutada pelos visitantes.

\subsection{Conclusões}

A partir do recorte metodológico utilizado nesta pesquisa, foi possível perceber que a gestão do

\footnotetext{
${ }^{29}$ Decreto Legislativo No 33 de 14 de março de 2013, disponível em: <http://www.normattiva.it/uri-res/N2Ls?urn:nir:stato:decreto.legislativo:2013-03-14;33>. Acesso em: jan.2016.

${ }^{30}$ Informações disponíveis em: <https:/www.facebook.com/parco.dellamaremma/>. Acesso em: mai.2016.

${ }^{31}$ Conteúdo sobre o parque disponível em: <https://www.instagram.com/parcomaremma/>. Acesso em: jul.2017.

${ }^{32}$ Disponível em: <https://www.youtube.com/channel/UCu6tjPgWMmI0a87Pn4Z1QYg>. Acesso em: jul.2017.

${ }^{33}$ Disponível em: <https://br.pinterest.com/parcodellamarem/>. Acesso em: jul.2017.
} 
Parque da Maremma vinha buscando ocupar espaços estratégicos para disseminação de informações, via internet, ainda que algumas redes sociais parecessem mais amplamente difundidas do que outras.

Neste contexto, dois aspectos centrais foram percebidos no processo de análise das ferramentas virtuais de comunicação dessa área protegida. Primeiro, a frequente atualização de informação sobre o parque e, também, a integração dos canais de informação disponíveis via internet. Assim, tanto no website oficial, como nas demais ferramentas online pesquisadas, a interconexão era facilmente percebida por meio de ícones que identificavam as mídias digitais utilizadas. Essa característica tende a facilitar o acesso dos internautas aos conteúdos divulgados em espaços variados e a aproximação do público, em geral, com o cotidiano da gestão dessa área protegida.

Desta forma, observou-se também que a opção pela utilização de ferramentas digitais para ampliar o diálogo com diversos tipos de público e, sobretudo, divulgar a temática da biodiversidade local tem sido reconhecida no âmbito da gestão dessa agenda. Um exemplo disso foi a inclusão de uma ação de comunicação e educação ambiental do Parque da Maremma em uma publicação da Federação Europeia de Parques Nacionais e Naturais (Europarc Federation, 2014). O trabalho reuniu algumas das melhores práticas comunicativas sobre gestão da natureza da União Europeia.

Por fim, cabe destacar, ainda, que além de ressaltar a relevância da estrutura para a região na qual se insere e de buscar facilitar a interatividade entre a sua equipe de gestão e a sociedade, os principais canais virtuais de disseminação de informação do Parque da Maremma também contribuíam, até então, para evitar o consumo de papel, uma das estratégias adotadas no âmbito do sistema de gestão ambiental dessa área protegida toscana.

\section{Considerações finais}

A comunicação desempenha um papel central, tanto na busca pela sensibilização da sociedade sobre a importância da biodiversidade para o bem-estar humano, como nos esforços de articulação de diferentes atores sociais para serem promovidas as mudanças necessárias ao alcance desse objetivo. Não por acaso, a Meta 1 de Aichi incide sobre a relevância de se ampliar o entendimento desta problemática pelos países signatários da Convenção sobre Diversidade Biológica (CDB). Esse pacto internacional também atua com base nessa orientação.

Considerando a relevância do tema em questão, a proposta deste artigo foi justamente de, a partir de dois casos distintos, um na América Latina (Parque Estadual da Ilha Grande) e outro na União Europeia (Parque Natural da Maremma), interpretar como vinham sendo desenvolvidas ações de gestão da informação, no sentido de buscar aproximar a sociedade dessa pauta complexa. Para tanto, teve-se como inspiração o que recomenda a Meta 1 de Aichi.

Diante do recorte escolhido e do percurso metodológico utilizado, percebeu-se que existiam nas duas áreas protegidas pesquisadas ações de comunicação em curso. Além disso, em ambos os casos, a relevância para o acesso da sociedade à informação era considerada como fundamental pelos interlocutores da gestão pública. Nesse sentido, vinham sendo utilizadas, sobretudo, ferramentas virtuais, a partir do reconhecimento do avanço alcançado pelos 
canais de comunicação via internet, bem como de suas funcionalidades e potencialidades.

Entretanto, em linhas gerais, no caso do Parque Natural da Maremma, na Itália, foi identificada maior agilidade e dinamicidade na utilização de espaços virtuais para a disseminação de informação sobre a gestão dessa área protegida e sobre a sua importância para a conservação da biodiversidade no contexto no qual se insere. Além disso, os principais canais de comunicação vinham promovendo a circulação de notícias e sinalizando alternativas para a interatividade entre os gestores e a sociedade. As ferramentas analisadas também vinham apontando mais integração entre si, o que, em tese, tende a potencializar os objetivos de disseminação de mensagens educativas e informativas.

Nessa perspectiva, no caso do parque italiano, parece haver uma clara tendência de alinhamento das ações desenvolvidas com as orientações da Meta 1 de Aichi. Porém, considerando a complexidade que envolve a agenda pesquisada, é importante enfatizar que, somente estudos específicos poderiam contribuir para mensurar o nível de compreensão dos internautas sobre os conteúdos disseminados, já que esse não foi o objetivo desta investigação. Entretanto, as interpretações trazidas por esta pesquisa podem inspirar a gestão dessa área protegida a promover levantamentos que avancem nessa direção.

Por outro lado, no caso do Parque Estadual da Ilha Grande, no Brasil, ainda que tenham sido identificados canais via internet para se promover o acesso à informação sobre a gestão dessa área protegida, foram observadas inúmeras deficiências no processo. As ferramentas de comunicação utilizadas vinham carecendo, por exemplo, de ampliação e de atualização de conteúdos veiculados.
Da mesma forma, a importância central desse parque para a conservação da biodiversidade na região ainda não vinha sendo abordada com o detalhamento necessário nas redes virtuais pesquisadas. É importante enfatizar que a linguagem disseminada nesses espaços precisa ser compreendida pelos diversos tipos de público e não somente por especialistas que buscam documentos oficiais e outros arquivos com dados científicos ou de legislação pertinente.

Por essas e outras razões que envolvem as ações de comunicação investigadas, é possível afirmar que o PEIG está ainda em fase inicial de mobilização para ampliar o entendimento da sociedade sobre as suas formas de gestão, assim como sobre a relevância da biodiversidade dessa área protegida para o bem-estar humano no contexto no qual se insere, conforme orienta a Meta 1 de Aichi.

Porém, cabe ressaltar, ainda, que precisam ser reconhecidas as distintas condições de gestão em cada área protegida pesquisada, além das diversas especificidades quando se trata de investigações acadêmicas em países com diferentes realidades socioeconômicas. Assim sendo, este recorte buscou ressaltar a importância de ambos os parques para o desenvolvimento das regiões em que se inserem. Mas a realidade atual de seus processos de gestão não é a mesma, o que tem efeitos evidentes nas ações de comunicação.

Frente às questões abordadas no contexto deste artigo, em especial no caso brasileiro, evidencia-se a necessidade de ser enfrentada a falta de integração e de atualização das informações disseminadas sobre o PEIG nas ferramentas oficiais pesquisadas. Da mesma forma, estudos para melhorar a compreensão sobre os perfis e as demandas dos internautas poderão contribuir nesse sentido. 
Certamente a solução desses problemas vai exigir ações em cooperação envolvendo não somente o órgão público responsável pela gestão do parque, mas, também, um maior esforço de instituições de pesquisa e outros segmentos sociais na construção de estratégias de comunicação mais eficientes e adaptadas à realidade da região.

Neste sentido, considerando que estão previstas reformulações nas ferramentas virtuais de disseminação de informação sobre o PEIG, conforme discutido anteriormente, avanços podem ser alcançados futuramente e os desdobramentos dessas iniciativas devem ser acompanhados por meio de novas investigações acadêmicas.

Finalmente, tendo em vista o processo de aceleração de perda de biodiversidade global e a necessidade de ampliação da compreensão da sociedade sobre a complexidade que envolve essa temática, a troca de experiências nacionais e internacionais de comunicação sobre o papel das áreas protegidas tende a ter uma importância cada vez mais central.

\section{Agradecimentos}

O trabalho de pesquisa que embasou a produção deste artigo foi possibilitado pelo apoio do Programa Doutorado Sanduíche no Exterior (PDSE) financiado pela Coordenação de Aperfeiçoamento de Pessoal de Nível Superior (CAPES).

\section{Referências}

Alho, C. J. R.; Schneider, M.; Vasconcelos, L. A. Degree of threat to the biological in the Ilha Grande State Park (RJ) and guidelines for conservation. Brazilian Journal of Biology, 62(3), 375-385, 2002. Disponível em: http://www.scielo. br/pdf/bjb/v62n3/12074.pdf

Araújo, P. R. Estado quer cobrança de taxa para visitantes na Ilha Grande. $O$ Globo, 04/06/2015. Disponível em: $<$ http://oglobo.globo.com/rio/estado-quer-cobranca-de-taxa-para-visitantes-na-ilha-grande-16049219>. Acesso em: jun.2016.

Bensusan, N. Diversidade e unidade: um dilema constante. Uma breve história da ideia de conservar a natureza em áreas protegidas e seus dilemas. In: Bensusan, N.; Prates, A. P. L. (Orgs.). A diversidade cabe na unidade? Áreas protegidas no Brasil. Brasília: IEB, p. 30-81, 2014.

Bimonte, S.; Pagni, R. Protezione, fruizione e sviluppo locale: aree protette e turismo in Toscana. Firenze: I R P E T - Istituto Regionale Programmazione Economica Toscana, 2003.

Bimonte, S.; Punzo, L. F. Tourism, residents' attitudes and perceived carrying capacity with an experimental study in five Tuscan destinations. International Journal of Sustainable Development, 14, 242-261, 2011. doi: 10.1504/ IJSD.2011.041964

Bimonte, S.; Faralla,V. Tourist types and hapiness: a comparative study in Maremma, Italy. Annals of Tourism Research, 39(4), 1929-1950, 2012.

Brasil. Lei $n^{\circ}$ 9.985, de 18 de julho de 2000. Institui o Sistema Nacional de Unidades de Conservação da Natureza - SNUC. Brasília: DOU de 19/07/2000.

Carvalho, A. Communication for sustainable policy: connecting science, society and government. In: Science for Environment Policy. DG Environment News Alert Service, Special Issue Environmental Communication. European Commission: 17, 1, 2009. Disponível em: http:// ec.europa.eu/environment/integration/research/newsalert/ pdf/17si_en.pdf

Catão, H. H. Ferreira; Carneiro, M. J. Conservação ambiental, turismo e população local. Cadernos EBAPE.BR, 3, 1-13, 2005. Disponível em: http://bibliotecadigital.fgv. br/ojs/index.php/cadernosebape/article/view/4929

Diegues, A. C. O mito moderno da natureza intocada. São Paulo: NUPAUB/USP, 1996.

Diegues, A. C.; Nogara, P. J. N. O nosso lugar virou parque: 
estudo socioambiental do Saco do Mamanguá - Parati - Rio de Janeiro. São Paulo: NUPAUB/USP, 2005.

Dovers, S.; Feary, S.; Martin, A.; McMillan, L.; Morgan, D.; Tollefson, M. 'Engagement and participation in protected area management: who, why, how and when?'. In: Worboys, G. L.; Lockwood, M.; Kothari, A.; Feary, S.; Pulsford, I. (Eds.). Protected Area Governance and Management. Canberra: ANU Press, p. 413-440, 2015.

Europarc Federation. Mobile apps about the species of Flora, Fauna and environments in Maremma Park. In: Best practices on communicating Natura 2000 sites (Action C.8.). Germany: LIFE+ Information and Communication Project: Efficient Managers for Efficient Natura 2000 Network, p.11-12, 2014. Disponível em: http://www.emenatura2000. ro/wp-content/uploads/2013/04/C.8.-Best-practices-on-communicating-Natura-2000-sites_LIFE-EME-2014.pdf

Fernandes-Pinto, E; Irving, M. A. Sítios naturais sagrados: valores ancestrais e novos desafios para as políticas de proteção da natureza. Desenvolvimento e Meio Ambiente, 40, 275-296, 2017. Disponível em: https://revistas.ufpr.br/ made/article/view/47843

Frome, M. Green ink: an introduction to environmental journalism. Salt Lake City: University of Utah Press, 1998.

Garcia, K. Parceria Público-Privada será a solução para a Ilha Grande? O Eco da Ilha Grande, 01/06/2016. Disponível em: <http://oecoilhagrande.com.br/index.php/2016/06/01/ parceria-publico-privada-sera-a-solucao-para-a-ilha-grande/>. Acesso em: jan.2017.

Giuliani, G. M. As unidades de conservação no Brasil e na Itália. Instituto Virtual de Turismo. In: Anais do I Seminário Áreas Protegidas e Inclusão Social (I SAPIS). Rio de Janeiro, 01-02 dez., 2005. Disponível em: $<$ http://www.ivtrj.net/ sapis/anais2005/mesas/mesa23.htm>. Acesso em: jun.2016.

Hamú, D.; Auchincloss, E.; Goldstein, W. (Eds.). Communicating Protected Areas. Gland, Switzerland and Cambridge, UK: Commission on Education and Communication, IUCN, 2004.

Hannigan, J. Sociologia ambiental. Petrópolis: Vozes, 2009.

Hesselink, F. J; Goldstein, W.; Kempen, P. P.; Garnett, T.; Dela, J. Comunicación, Educación y Conciencia Pública.
Una caja de herramientas para personas que coordinan las Estrategias y planes de acción nacionales sobre diversidad biológica. Montreal: SCDB; UICN, 2007.

INEA - Instituto Estadual do Ambiente do Rio de Janeiro. Plano de Manejo (Fase Dois) do Parque Estadual da Ilha Grande. Rio de Janeiro, 2011. <http://www.inea.rj.gov.br/ cs/groups/public/documents/document/bmvh/mdey/ edisp/ inea012819.pdf>. Acesso em: jul.2016.

INEA - Instituto Estadual do Ambiente do Rio de Janeiro. Plano de Manejo (Fase 2)/Resumo Executivo. Parque Estadual da Ilha Grande (PEIG). Rio de Janeiro, 2013. $<$ http://www.inea.rj.gov.br/cs/groups/public/documents/ document/zwew/mdiw/ edisp/inea0020167.pdf $>$. Acesso em: jul.2016.

Irving, M. A. Áreas protegidas e inclusão social: uma equação possível em políticas públicas de proteção da natureza no Brasil? Sinais Sociais, 12, 122-147, 2010. Disponível em: http://www.sesc.com.br/portal/publicacoes/sesc/revistas/ sinaissociais/n12/n12

Irving, M. A.; Oliveira, E. Sustentabilidade e transformação social. Rio de Janeiro: Senac Nacional, 2012.

IUCN - International Union for Conservation of Nature. Guidelines for protected areas: management categories. Gland: International Union for Conservation of Nature IUCN, World Conservation Monitoring Centre - WCMC, 1994.

Lewinsohn, T.; Prado, P. I. How Many Species Are There in Brazil? Conservation Biology, 19(3), 619-624, 2005. doi: 10.1111/j.1523-1739.2005.00680.x

MATTM - Ministero dell 'Ambiente e della Tutela del Territorio e del Mare. Aree naturali protette. Italia, 2014. $<$ http://www.minambiente.it/pagina/aree-naturali-protette $>$. Acesso em: jun.2016.

MMA - Ministério do Meio Ambiente. Convenção sobre Diversidade Biológica (CDB), Brasília, 2000.

MEA - Millenium Ecosystem Assessment. Ecosystem and human well-being: synthesis, 2005. <www.millenniumassessment.org/documents/document.356.aspx.pdf>

Neves, E. M. S. C. Política ambiental, municípios e cooperação intergovernamental no Brasil. Estudos Avançados, 
26(74), 137-150, 2012. Disponível em: http://www.scielo. br/pdf/ea/v26n74/a10v26n74.pdf

Oliveira, L. F. Ecoturismo no Parque Estadual da Ilha Grande-RJ: refletindo o contexto atual a partir do olhar dos "badjecos". Rio de Janeiro, Dissertação (Mestrado em Psicossociologia de Comunidades e Ecologia Social) - UFRJ, 2008.

Oliveira, E.; Irving, M. A. Convenção sobre Diversidade Biológica pós Nagoya: desafios para a mídia em um país de megadiversidade. Razón y Palabra, 75, 1-26, 2011. Disponível em: http://www.razonypalabra.org.mx/N/N75/ varia_75/varia3parte/40_Oliveira_V75.pdf

Pellizaro, P. C.; Hardt, L. P. A.; Hardt, C.; Hardt, M.; Sehli, D.A. Stewardship and management of protected natural areas: the international context. Ambiente \& Sociedade, 18, 19-36, 2015. Disponível em: http://www.scielo.br/pdf/asoc/ v18n1/1414-753X-asoc-18-01-00019.pdf

Prates, A. P. L.; Irving, M. A. Conservação da biodiversidade e políticas públicas para as áreas protegidas no Brasil: desafios e tendências da origem da $\mathrm{CDB}$ às metas de Aichi. Revista Brasileira de Políticas Públicas, 5, 27-57, 2015. Disponível em: https://www.publicacoesacademicas.uniceub.br/RBPP/article/view/3014

Regione Toscana Giunta Regionale. Turismo ecocompatibile e servizi di qualità nel Parco della Maremma. In: Aree naturali protette della Toscana non solo conservazione: esperienze e proposte di gestione. Italia: Assessorato Difesa del suolo e servizio idrico integrato, p.37-40, 2009.
SCBD - Secretariat of the Convention on Biological Diversity. Global Biodiversity Outlook 3. Montréal, 2010. < https://www.cbd.int/doc/publications/gbo/gbo3-final-en. pdf $>$. Acesso em: jul.2016.

United Nations. The Johannesburg Declaration on Sustainable Development. Johannesburg. 2002.< http://www. un-documents.net/jburgdec.htm>. Acesso em: abr.2016.

UICN; WWF-Brasil; IPÊ. Metas de Aichi: Situação atual do Brasil. Brasília, 2011.

Vallejo, L. R. Conflitos territoriais em parques estaduais do Rio de Janeiro: uma avaliação à luz das políticas de governo. Revista geo-paisagem (online), 7, 1-28, 2005a. Disponível em: http://www.feth.ggf.br/Parque.htm

Vallejo, L. R. Políticas Públicas e Conservação Ambiental territorialidades em conflito nos Parques Estaduais da Ilha Grande, Serra da Tiririca e Desengano. Niterói, Tese (Doutorado em Geografia) - UFF, 2005b.

Venturi, L. I. Parco regionale della Maremma, uno "splendido quarantenne". Portal Greenreport.it. 19/06/2015. Disponível em: $<$ http://www.greenreport.it/news/aree-protette-e-biodiversita/il-parco-regionale-della-maremma-uno-splendido-quarantenne/>. Acesso em: jul.2015.

Viola, E. A Globalização da política ambiental no Brasil, 1990-1998. In: Anais do XXI International Congress of the Latin American Studies Association. Chicago, 24-26 set., 1998.

Wilson, E. O. (Org.). Biodiversidade. Rio de Janeiro: Nova Fronteira, 1997. 